pyrites are totally inpermeable; chalcopyrite and zinc blende possess a very small permeability and ironspar a considerably greater, although much smaller than that of magnetite. The arrangement used in cryolite-separation is roughly sketched in Fig. 2. The two leveled poles $A$ of a very strong electromagnet are placed above a felt cloth, B. An endless belt, C, carries the mixture of minerals into the magnetic field. Cryolite and galena drop straight down as soon as they leave the belt, while zinc blende and chalcopyrite go a little further and drop into a separate
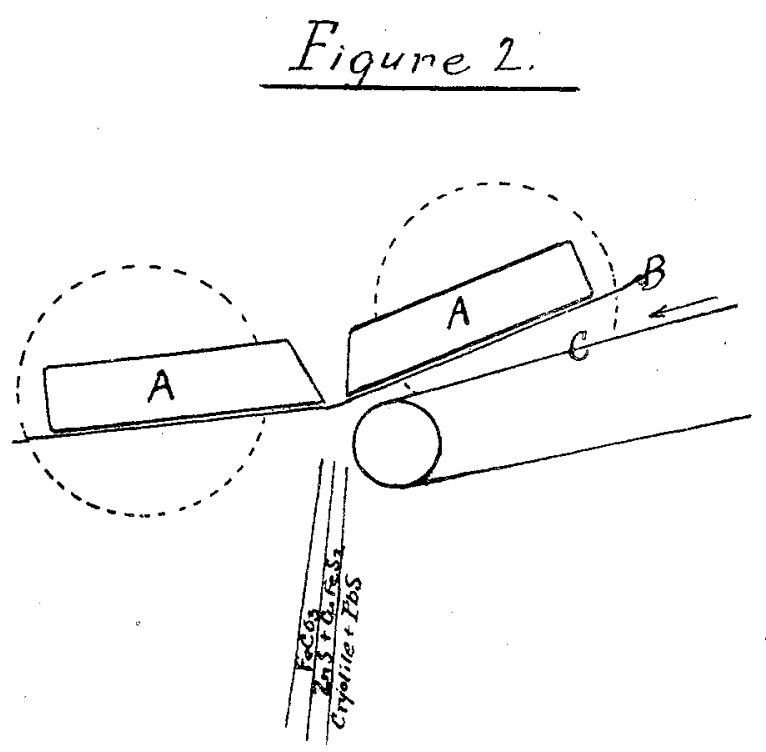

slit. The ironspar goes still further and is gathered through a third channel. There is always a small amount of magnetite present, which by and by would stick in a solid mass to the felt cloth and interrupt the work if not removed. This is done by passing the mass of minerals previously through a weak magnetic field. The first product from the jigs yields after this separation a pure cryolite, while the second product yields a mixture of cryolite with some galena. A following jigging separates them completely.

The purified cryolite is either sold in lumps or ground to a fine powder on a chaser mill. A careful grinding allows here a separation from a small amount of quartz still present, as the quartz is not ground so easily and can be removed by a subsequent sifting.

The separated gangue minerals possess some value. The ironspar is sold to steel plants and the galena and chalcopyrite which contain traces of silver and gold respectively go to a smelter.

It would probably not pay to subject a cheap mineral to such a complicated treatment as that above described, but cryolite is relatively high-priced-it sells around $\$ I 60$ per ton. The cryolite-separation as described is to the writer's knowledge only carried out at the "Oresund Chemical Works," Copenhagen, Denmark.
ON THE INTERPOLATION METHOD OF OIL ANALYSIS. ${ }^{1}$

By J. I. Kessler and G. K. Mathrason. Received December 14, 1910.

The methods of analyzing oil mixtures may be reviewed under three divisions:

First.-Those methods which depend upon a separation of the constituent oils, or their derivatives.

Second.-The qualitative identification of one oil in the presence of another, by means of color reactions, odor, etc.

Third.-The determination of some of the physical constants of the mixture of oils and the use of such data in drawing conclusions as to the percentage of each constituent present.

Of these three general methods, the first one, by far the most satisfactory in principle, has unfortunately very limited application. A separation of the constituent oils is many times either impossible or impractical.

The constituent oils of a mixture are generally soluble in one another in all proportions at ordinary temperatures, and separation by fractional crystallization is not possible. Again, the oils are more or less decomposed by distillation, and a clean separation is, except in very special cases, impossible.

As an illustration-hydrocarbon oils may be separated from ester oils by saponification, but, of course, the method is limited to those cases where hydrocarbon oils are present.

The second set of methods, the qualitative identification of one oil in presence of another, by means of reactions producing characteristic colors, while of the very greatest qualitative value, has very limited application. Many such color reactions will be recalled.

Among the most valuable are the LiebermannStorch reaction for the identification of rosin oil, rosin and cholesterol, the Bechi, Halphen and Brulle tests for cottonseed oil; the Villavecchia test for sesame oil, etc., etc.; of very limited usefulness are the color tests with nitric and sulphuric acids.

The only method of perfectly general application, the third set of methods, may be called interpolation methods, because one calculates a percentage composition from certain physical constants of the mixture, after assuming values of the corresponding constants for the pure oils. The inherent weaknesses of such procedure need only a rapid review. The first and greatest difficulty lies in the fact that a commercial oil, whether a mineral, a seed, an animal or a fish oil, has an individual character, depending upon the condition of the source of the oil, the method of obtaining the oil, method of refining, of storing, the age and the conditions under which the oil is kept. The fundamental necessity of exact interpolation is, therefore, lacking. We ought to know the particular constants of the particular oils in the mixture in order to obtain exactness, and this is impossible.

Our literature does not give us the assistance that it should in this respect. It is too general. Lewkowitsch, for instance, will give us constants from 
different observers, working at widely different periods, on oils of continental or British origin, and which have been obtained by methods differing widely in details. We ought to have, on the other hand, tables showing constants for the oils actually on the American market, which constants have been obtained by standard methods. We are now beginning to get such information.

The cottonseed oil literature is very extensive; so is that of linseed oil, and the government bulletins are of the very greatest service both as to standardization of methods and the compilation of up-to-date analytical results. No doubt, the time is near at hand when we will be able to get the best of such work collected together and easily available.

A second difficulty lies in the fact that the constants of many oils have approximately similar values, while the precision of an interpolation of any sort depends partly upon the condition that one variable changes rapidly for a correspondingly small change of the other.

A third difficulty lies in the very generality of the method. The physical constants obtained may apply equally well to many different mixtures. A gravity of 0.920 , for instance, does not define any particular oil or mixture of oils. It must be used with other data in enabling the oil chemist to proceed with the logic he uses in reaching his results.

From the foregoing is seen the difficulty of obtaining an exact analysis by the interpolation method.

On further consideration of the requirements for exact interpolation, we must not forget one very important point, a point next in importance to the requirement of having exact end points. This point is not mentioned nor discussed in works on oil analysis, and while we cannot believe that it does not occur in many places in some of the many papers that have been written on the subject, it is certainly not a part of the general literature.

The requirement referred to is that the form of the functional relationship between composition on the one hand and property on the other shall be known.

Geometrically this means, of course, the determination of the shape of the curve joining the two end points, or, if three oils are present in the mixture; the shape of the surface joining the three end points. As stated, we do not find any explicit statement on this question in the general works on oil analysis. The inference of the chemist is, we believe, that the curve is a straight line.

Stillman ${ }^{x}$ gives a formula for calculating the composition of a mixture of two oils, after assuming the kinds of oils present, their Maumené test, and using the observed Matumené test.

This formula is based on the assumption that the temperature rises of a mixture of oils is proportional to the temperature rise of the constituent oils, and the relative amounts present. It is assumed here, therefore, that the relationship is additive, that the law of the mixture of oils, as far as this test is concerned, is a straight line.

1 Edition 1900, "Engineering Chemistry."
We wish to present some experimental data on this point. Our plan of work has been to take certain commonly used oils, make mixtures of them, obtain constants on these mixtures, and plot the results against the composition, in order to obtain an insight into the law of the mixture.

The oils used in this work were castor oil, cottonseed oil, linseed oil, a rosin and a mineral oil. The rosin and mineral oils were selected with reference to their having viscosities similar to those of linseed and cottonseed oils, such oils, in other words, as might be used in the adulteration of linseed or of cottonseed oils. Some care was used in selecting these oils, in order to be sure that the oils were in the first place pure oils, and in the second place, that they were representative oils; that is, that their constants were average constants. In each case the oil was obtained in a barrel quantity, and bore the name of the crusher, or refiner.

The castor oil was a No. I castor oil, and was obtained from the Waters-Pierce Oil Company. The barrel bore the label of the Robert B. Brown Oil Company. The linseed oil was obtained from the American Linseed Co., direct from their warehouse. It was designated as "Pure Pressed Raw Linseed Oil-Old Process." The cottonseed oil was obtained from the Proctor \& Gamble Co. It was designated as "White Clover Cooking Oil," and was a summer-bleached oil. The mineral oil was obtained from the Waters-Pierce Oil Co. It was designated as "Paraffine Oil." The rosin oil was obtained from the American Naval Stores Co., and was shipped to us direct from Savannah. It was designated as "No. 2 Rosin Oil."

Our method of working was to make up approximately I000 gram samples, by direct weighing of the constituents. We made seven different mixtures of each set of two different oils. The percentages chosen were $2,5,20,50,80,95$ and 98 per cent. It will be noticed that our observational points were chosen unevenly along the composition line, in order to crowd our observations near the end points. This was for the purpose of enabling us to study the influence of a small quantity of one oil in another. We made up, therefore, combinations of five oils, two at a time, each of which were made up in seven different mixtures, or seventy different samples in all.

The tests that were studied were as follows: The acid No., saponification No, density, flash test, together with the fire test, Maumene test, and viscosity at $70^{\circ} \mathrm{F}$. The saponification No. and viscosity were made in duplicate in each case, and the other tests in duplicate where the results showed a larger accumulation of experimental error than was considered allowable. In some instances where the acid number was very small in both members of a mixture, the determination was omitted for that particular mixture.

The methods used for making the tests named were as follows:

Acid No.-Ten grams of the sample were weighed into an eight-ounce oil bottle. $20 \mathrm{cc}$. 95 per cent. ethyl alcohol were added and the mixture shaken thoroughly. The mixture was titrated with $N /$ io 
potassium hydrate solution, in water, using phenolphthalein as an indicator. Blanks were run on the alcohol and the amount of caustic potash required for neutralization subtracted from the reading for the sample. The blanks did not require more than o. I cc. potassium hydrate for neutralization.

The end point taken was that obtained when the pink color persisted after vigorous shaking. The acid number calculated from the burette readings was the number of milligrams of potassium hydrate required to neutralize the acids present in I gram of the sample.

Saponification No.-Approximately $\mathrm{I}^{\mathrm{I}} / 2$ grams of oil were weighed into an eight-ounce oil bottle, the oil being accurately weighed on a chemical balance, using the pycnometer used in the determination of density as a weighing bottle. Duplicate samples were weighed out in each case. $20 \mathrm{cc}$. alcoholic potash were added and the mixture heated on a water bath at $80^{\circ} \mathrm{C}$., from 30 to 40 minutes. The samples were thoroughly shaken several times while saponification was going on. After cooling, the mixture was titrated with $N / 2$ hydrochloric acid, using phenolphthalein as an indicator. Two blanks of $20 \mathrm{cc}$. each of alcoholic potash were run through with the samples each time and the mean of the results used in calculating the potash used in the saponification. The alcoholic potash solution was made up with 30 grams $\mathrm{KOH}$ dissolved in a small amount of water, and made up to I liter with 95 per cent. ethyl alcohol, and allowed to stand over night. The saponification No. calculated from the burette readings was the number of milligrams of caustic potash required to saponify one gram of the sample.

Specific Gravity.-Specific gravity determinations were made in all cases with the commonly used form of pycnometer, holding in each case between 25 and $30 \mathrm{cc}$. of oil. All determinations were made at $21^{\circ} \mathrm{C}$. within a degree on each side.

Flash Test.-An open iron cup was used in making this test. The cup held $75 \mathrm{cc}$. of oil and was filled. to within $3 / 8$ of the top of the cup. The oil was heated at the rate of $3^{\circ} \mathrm{C}$. per minute, over a Bunsen burner.

Fire Test.-The fire test was taken at that temperature at which the oil first began to burn continuously upon application of the small flame. Both flash and fire tests are recorded in degrees centigrade.

$V$ iscosity. - The viscosity was measured in a standard Tagliabue instrument. Readings were made at $2 \mathrm{I}^{\circ} \mathrm{C}$., and the temperature of the oil kept in all cases to within $\mathrm{I} / 2^{\circ} \mathrm{C}$. on a side. The figure for viscosity given is that obtained from the number of seconds required for $70 \mathrm{cc}$, of the oil to run out multiplied by two, this being the amount of oil and the standard method of calculating recommended by the makers. $70 \mathrm{cc}$. of distilled water ran through this instrument in 23 seconds, at a temperature of $70^{\circ} \mathrm{F}$., making the viscosity of water at this temperature 46 , with this instrument and method. The temperatures were regulated by pouring warmer or colder water into the jacket surrounding the instrument. All figures given are the mean of two different readings made on the same sample.

Maumene Test.-Fifty grams of the sample were weighed into a No. 3 beaker which was placed inside a No. 4 beaker. The larger beaker was prepared by filling the space between the two beakers with a mixture of plaster of Paris and asbestos. After drying, the inside beaker may be removed and replaced by another of the same size. Since many of the samples tested frothed badly, particularly the cottonseed oil and linseed oil mixtures, a much higher form of beaker was used in these cases. Ten cc. sulphuric acid were added to the oil from a burette, during one minute. Stirring was effected by using a simple device, the object being to use the same conditions of stirring as possible during all of the tests. Instead of noting only the maximum temperature reached by the thermometer, we read the temperature each half minute until the thermometer showed a falling temperature. In this way we were certain of the actual maximum rise of temperature in all cases, and were able to observe some interesting facts with reference to the development of heat, by the mixture. The Maumene test is the maximum temperature rise obtained, subtracting from the thermometer reading the temperature of the oil and acid, which was kept at the temperature of the room. In some cases we found that a higher temperature rise may be obtained if the stirring is discontinued after the oil and acid are mixed. We attempted to use in all cases that condition of stirring which would give the maximum temperature rise.

Discussion of Results.

Acid No.-The acid No. was determined on these mixtures of oils principally as a check upon the composition of the samples. They have not been made in a few mixtures, since some of the oil mixtures contain practically no free acids. These tests bring out the fact that the acid number is accurately determined by the method shown for all combinations of oil, whether they contain large amounts or small amounts of free acids.

Saponification No.-These tests were carried out in order to determine principally whether the saponifcation of a small amount of saponifiable oil is completely effected under the ordinary conditions of the test, when a large amount of unsaponifiable oil is present. The tests indicate that such is the case, and that the saponification number is readily obtained in all sorts of mixtures.

Gravity.--Specific gravity determinations were made as a further check upon the composition of the sample. Since the samples were made up by weight, and not by volume, it would not be expected that the curve showing gravity plotted against composition by weight would be strictly a straight line, although it plots nearly as a straight line, since the density of the oils were nearly unity. This is a simple illustration of the fact that additive relationships may not be found in some cases from purely algebraic reasons.

Flash Test.-The results on flash tests show very clearly that this phenomenon is not necessarily an 
additive one. In those cases where there is any great difference between the flash points of the constituent oils, a very considerable curvature is to be found. In the cottonseed-linseed, and cottonseed-castor oil mixtures, where the flash tests of the constituent oils are nearly the same, the curvature is not apparent, and if it exists, lies within the range of observational errors.

Fire Test.-These results have not been plotted, but are similar to those obtained from the flash test.

Viscosity. - The curves of viscosity show considerable deviations from the additive relationship. We obtained indeed such curves even in these cases where the viscosity of the constituent oils is nearly the same. Nor do we obtain straight lines when we plot fluidity against composition. We believe those results are of interest, as an indication of the fact that neither the viscosity nor the fluidity of such solutions are necessarily additive, even though there is no evidence to indicate that either chemical or molecular compounds are formed.

Maumene Test.-Our results on Maumene tests indicate, on the whole, that the results are not additive, but that in mixtures containing a high Maumené test oil and a low Maumené test oil, that the results are greater than calculated from the law of averages at the upper end of the curve and lower than that calculated from the law of averages at the lower end of the curve. In no case were we able to duplicate the Maumene test on any given mixture within a degree, or even within several degrees, when tests were made time after time, or day after day, upon the same sample. We have tried to use every possible precaution with reference to duplicating the conditions of the test time after time, but we have found this test to give most unsatisfactory results, and we consider it almost useless as a quantitative method.

Of the different factors which determine the rise in temperature of a mixture of oil and sulphuric acid, there seems to be quite a few which are beyond the control of the operator, and the result is that the different samples of the same oil mixture will give temperature rises that differ between themselves as much as $5^{\circ}$ and even $10^{\circ}$ centigrade.

We have found that the rate of stirring has an important influence upon the result, and our experience has been that a method of stirring must be used which differs with different mixtures, in order to get the highest temperature rise.

This seems to be due to the fact that the stirring has two different effects: it tends to mix the oils intimately with the acid, and it also assists in the cooling of the mixture. Consequently, after stirring has mixed the oil and the acid thoroughly, further stirring only assists in the loss of heat by the mixture. This carries with it, of course, the assumption that the oil and acid stay mixed.

The more viscous the oil the greater the tendency to stay mixed. Oils containing castor oil do not require more than a certain amount of stirring. Mixtures containing a large amount of oils of low viscosity require constant stirring in order to keep the acid in contact with the oil.
There are other important factors, however, which influence the development of heat in a mixture of oils and sulphuric acid. The reaction appears to be a function of the temperature itself, which is in its turn a function of the velocity of the reaction. Any condition which influences the initial velocity of the reaction, therefore, has an influence upon the quantity which is under observation, which is the maximum temperature rise.

If the reaction starts off briskly the total rise will be correspondingly higher than is the case where, for some reason, the velocity of the reaction is slower at the beginning.

We think it probable that it is this dependence of the quantity of the reaction upon its own velocity that interferes so seriously witl its yielding results which may be duplicated within satisfactory limits.

\section{SUMMARY OF RESULTS.}

Certain tests commonly used in oil analysis (the viscosity, flash test, fire test and Maumené test) have been shown to follow a law of mixtures which is not an additive one, and hence if interpolations are made from the data obtained from such tests, the results will be in erros, to a very considerable amount in some cases.

These results call attention to the possibility of many other physical tests being non-additive. They also suggest the possibility that certain chemical tests, in which a complete chemical reaction does not occur, may not be additive.

The saponification No. is shown to be an additive relationship even for small percentages of one oil in presence of another.

The Maumené test as carried out at the present time is incapable of yielding results which can be used in making a quantitative analysis by the interpolation method.

Work is being done at the present time upon the iodine Nos. of these oil mixtures.

NOTES ON THE TABULATED RESULTS AND CURVES.

The tabulated results show the figures obtained on all of the tests made.

In the case of some of the mineral oil-castor oil mixtures the constituent oils are not soluble in one another at ordinary temperatures. These mixtures were analyzed, however, together with the rest of the samples, the mixture being very thoroughly shaken before the sample for the test was taken out of the bottle. These mixtures are marked in the tables with a star:

The viscosity, saponification No., flash test and specific gravity have been plotted in the curves. Observational points are shown by small circles. In the case of the saponification Nos. the diameter of this circle indicates a difference of saponification No. of 4 ; in the case of specific gravity the diameter of the circle indicates a difference of specific gravity of 0.0020 ; in the case of the flash tests the diameter of the circle indicates a difference of temperature of $4^{\circ} \mathrm{C}$. In the case of viscosity the diameter of the circle indicates a difference of 4 when castor oil is absent and a difference of 40 when castor oil is present. 


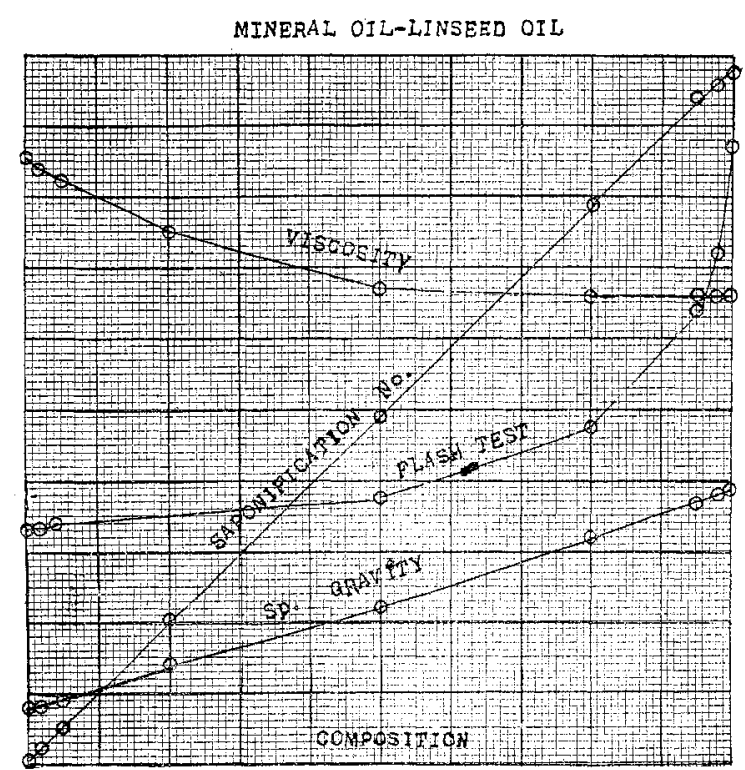

MINERAL OIL-COTTONSEED OIL

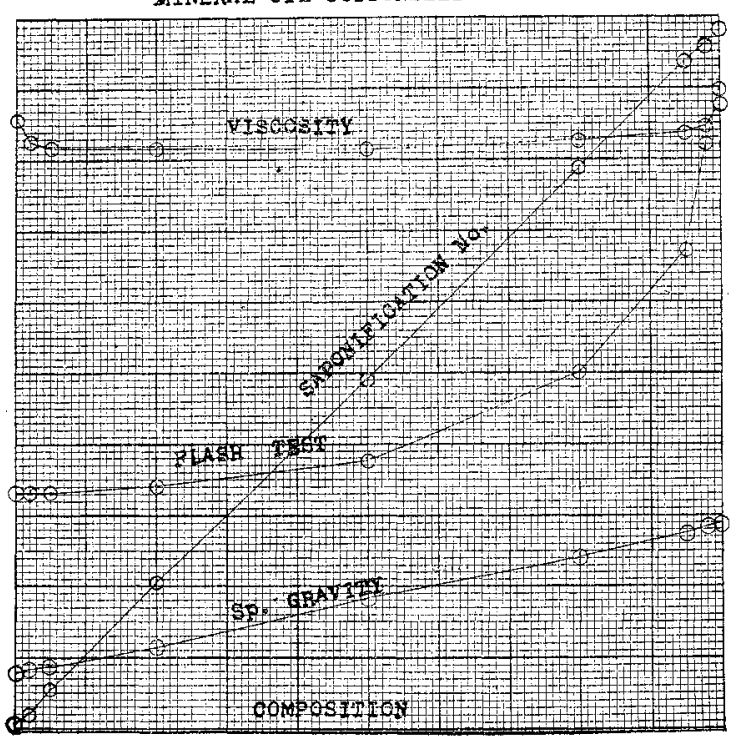

LINSEED OYL-ROSIN OIL

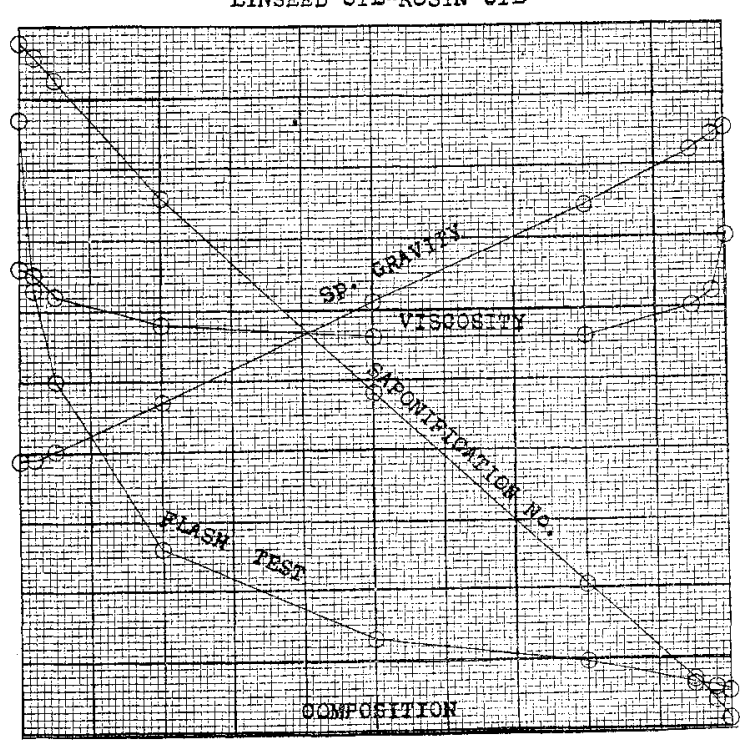

LINSEED OILMASTOR OIL
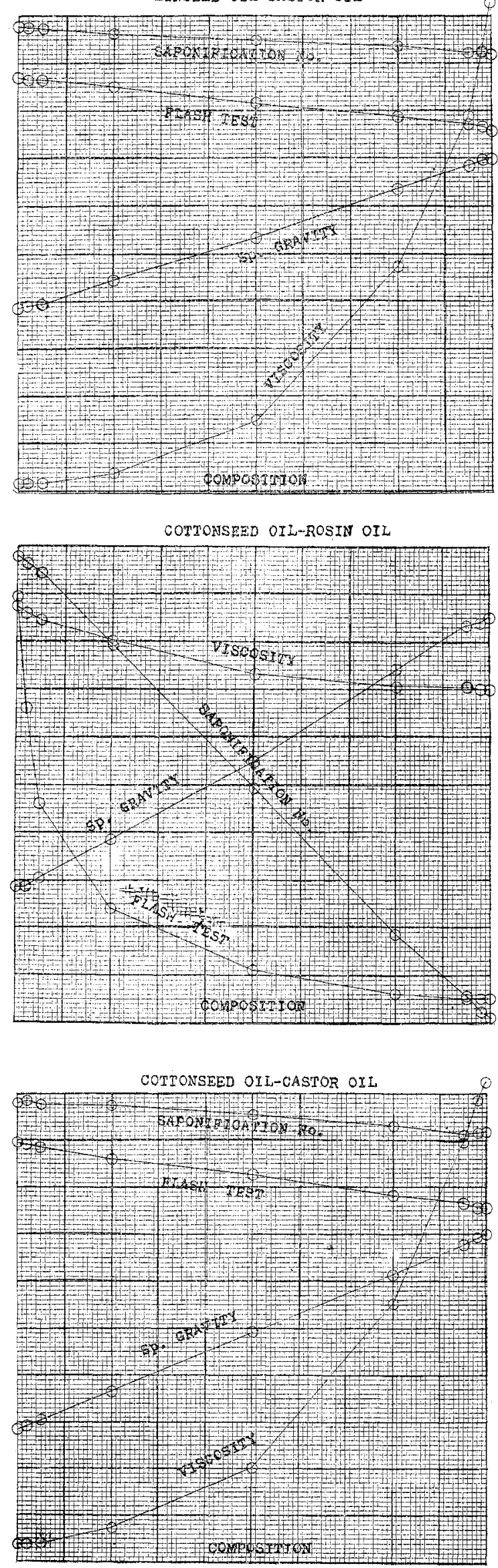
COTRONSEED OIL-LINSEED OIL
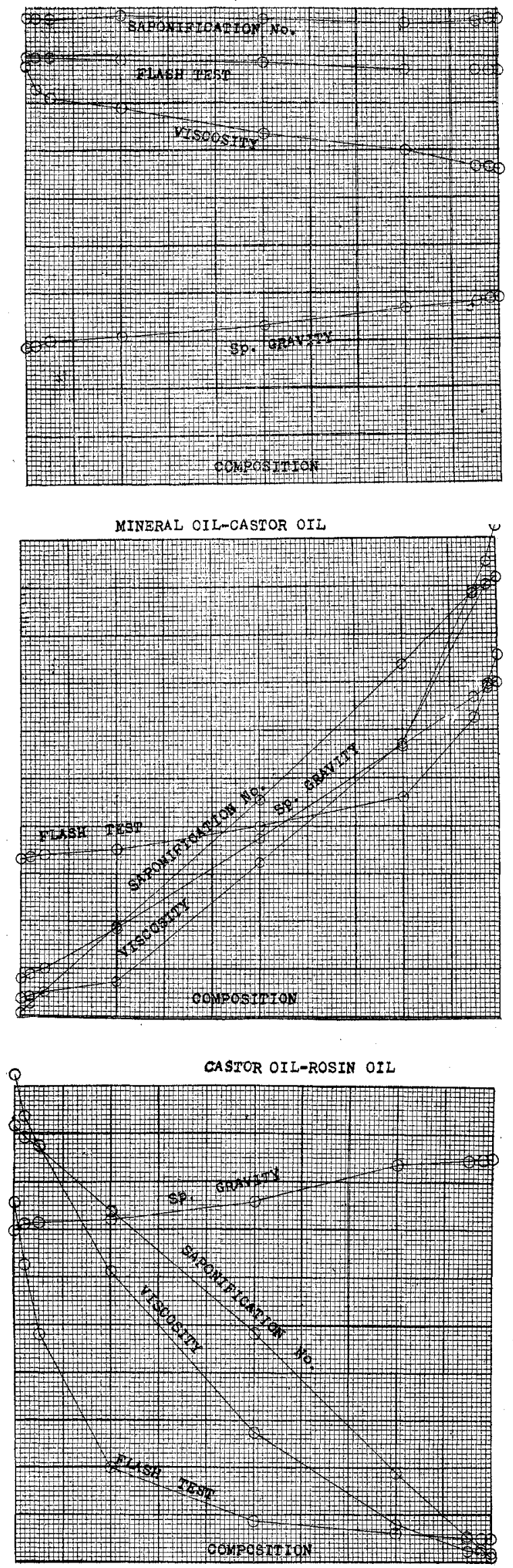

MINERAL OIL-ROSIN OIL
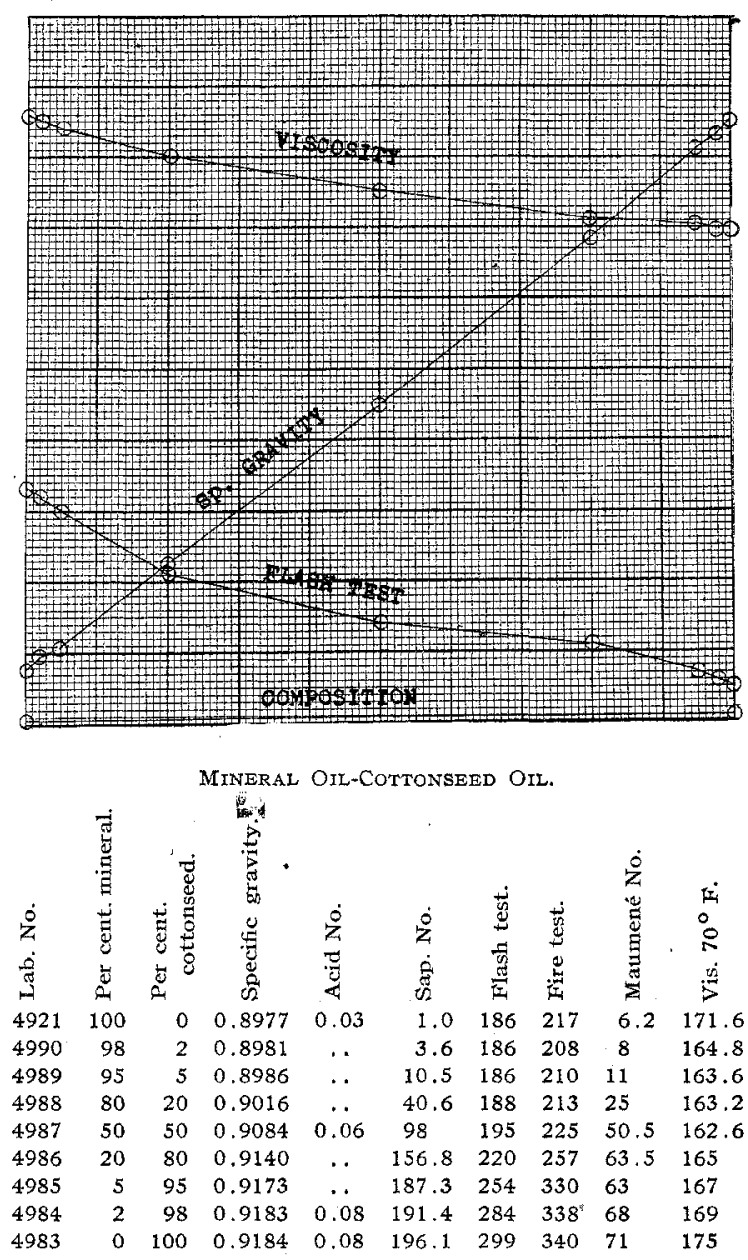

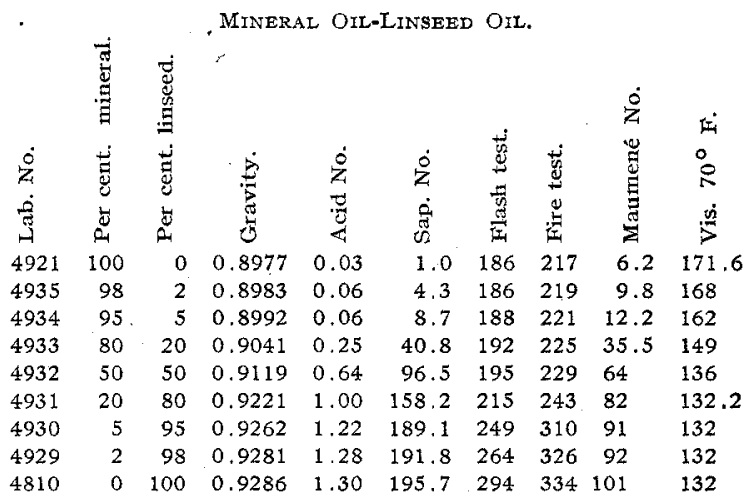

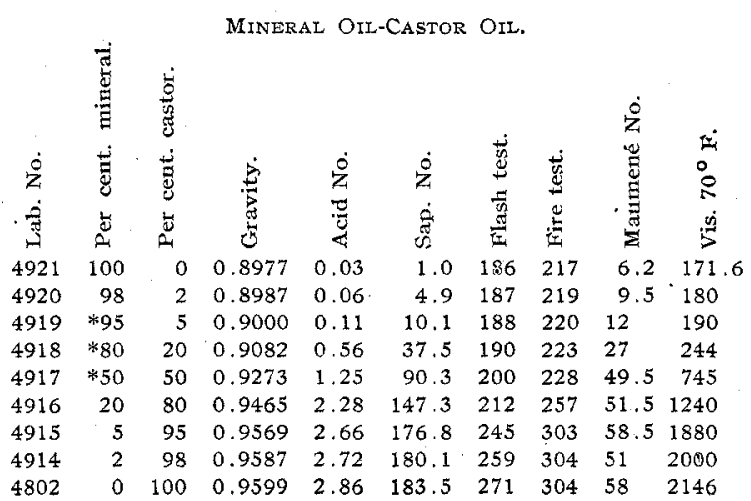



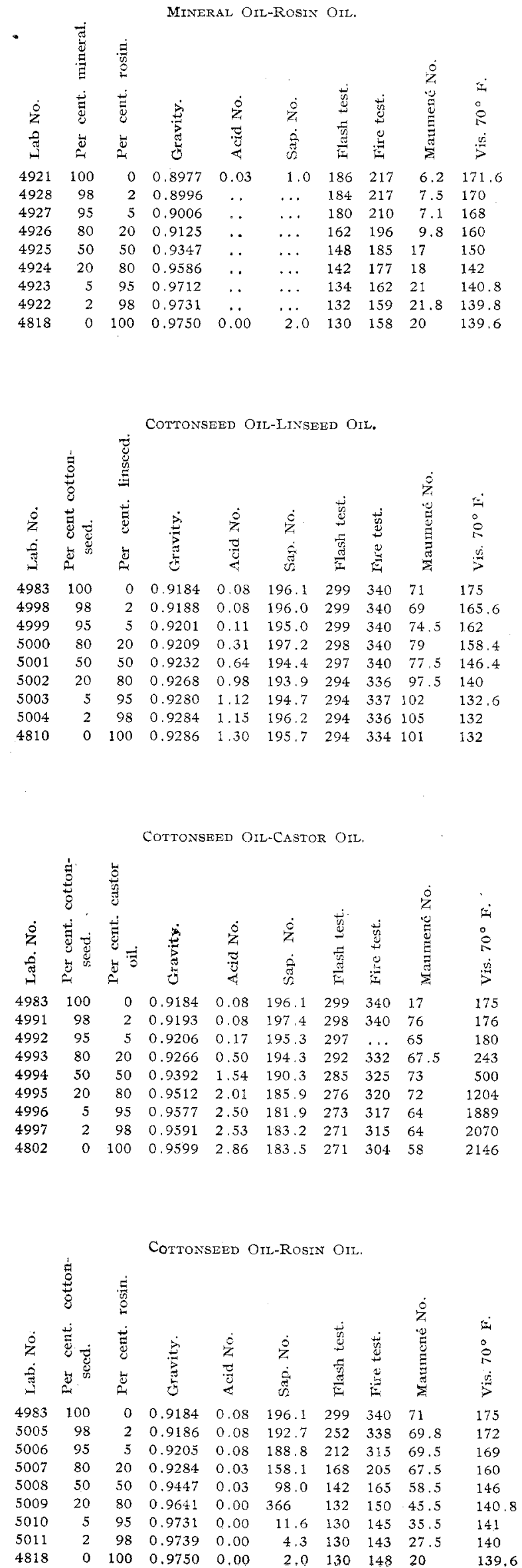
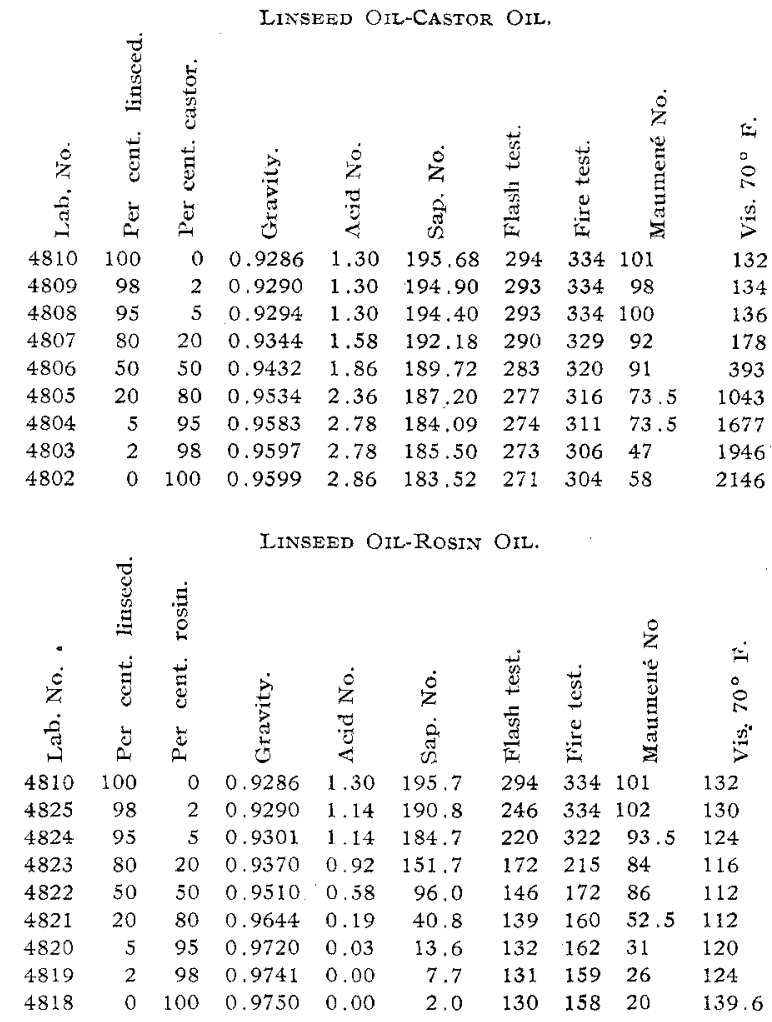

\section{A COMPARISON OF METHODS OF DETERMINING UN- SAPONIFIABLE MATTER IN WOOL OILS.}

By Aqgustus H. Gill AND A. E. Shippee. Received December 23, 1910.

There are two methods in common use for determining unsaponifiable matter in wool oils, the usual extraction method with gasoline, and the method by difference. In the latter method the free acid is determined, then the combined fatty acids, these latter calculated as olein, added to the free acid, and this sum subtracted from Ioo, giving the unsaponifiable matter. As this method is more rapid, and is quite extensively used, it seemed advisable to compare it with the other.

Procedure: Extraction Method.-The free fatty acids, unsaponifiable matter and saponification number were determined according to the procedure given in Gill's "Oil Analysis." 